\title{
Optimisasi Perencanaan Produksi Pupuk Menggunakan Firefly Algorithm
}

\author{
Dinita Rahmalia ${ }^{1}$, Awawin Mustana Rohmah ${ }^{2}$ \\ Universitas Islam Darul Ulum Lamongan ${ }^{1}$, dinitarahmalia @ gmail.com ${ }^{1}$ \\ Universitas Islam Darul Ulum Lamongan², awawin.emer@gmail.com ${ }^{2}$
}

DOI:https://doi.org/10.15642/mantik.2018.4.1.1-6

\begin{abstract}
Abstrak
Di Indonesia, terdapat banyak petani sebagai matapencaharian karena tanah yang subur untuk pertanian serta kebutuhan akan pangan. Perencanaan produksi merupakan bagian penting dalam mengelola biaya yang dikeluarkan perusahaan. Pada perencanaan produksi, terdapat kendala yang harus dipenuhi misal : jumlah produksi, jumlah pekerja, dan jumlah pengadaan. Pada penelitian sebelumnya, optimisasi berkendala telah diselesaikan menggunakan metode eksak maupun metode heuristik. Pada penelitian ini, model optimisasi perencanaan produksi akan diselesaikan menggunakan Firefly Algorithm (FA). Cara kerja FA menyerupai perilaku kunang-kunang. Salah satu perilaku kunang-kunang yang digunakan adalah kunang-kunang yang kurang cerah akan mendekati kunang-kunang yang lebih cerah. Hasil simulasi menunjukkan bahwa metode FA dapat menemukan pendekatan solusi optimum pada perencanaan produksi yaitu biaya produksi, biaya pekerja, dan biaya pengadaan yang memenuhi kendala jumlah produksi, jumlah pekerja, dan jumlah pengadaan.
\end{abstract}

Kata kunci: Optimisasi Berkendala, Perencanaan Produksi, Firefly Algorithm

\begin{abstract}
In Indonesia, there are many farmers as a livelihood because of fertile soil for agriculture and the demand for food. Production planning is the important part of managing cost spent by the company. In production planning, there are many constraints which have to be satisfied such as the number of productions, the number of workers, and the number of inventory. In previous research, constrained optimizations have been solved by exact method or heuristic method. In this research, production planning optimization will be solved by Firefly Algorithm (FA). FA works as a behavior of Firefly. One of firefly behavior used is less bright firefly will move toward brighter firefly. The simulation results show that FA method can find an approaching optimal solution of production planning like production cost, worker cost, and inventory holding cost satisfying the constraints of the number of productions, workers, and inventory.
\end{abstract}

Keywords: Constrained Optimization, Production Planning, Firefly Algorithm

\section{Pendahuluan}

Di Indonesia, terdapat banyak petani sebagai matapencaharian karena tanah yang subur untuk pertanian serta kebutuhan akan pangan. Karena permintaan produksi pertanian, perusahaan yang

bergerak pada bidang pertanian, yaitu perusahaan produksi pupuk memproduksi pupuk untuk didistribusikan pada petani. Pada proses ini terdapat biaya yang ditimbulkan seperti biaya produksi dan perusahaan harus membuat perencanaan untuk mengendalikan pendapatan, biaya, dan produksi.

Perencanaan produksi merupakan bagian penting dalam mengelola biaya yang dikeluarkan perusahaan. Pada perencanaan produksi, terdapat kendala yang harus dipenuhi misal : jumlah produksi, jumlah pekerja, dan jumlah pengadaan. 
Dari model perencanaan produksi tersebut, dapat dibentuk optimisasi berkendala.

Pada penelitian sebelumnya, optimisasi berkendala telah diselesaikan menggunakan metode eksak [1][8] maupun metode heuristik [7] seperti Genetic Algorithm (GA) [5], Particle Swarm Optimization (PSO) [4], Ant Colony Optimization (ACO) [3], Artificial Bee Colony (ABC) [6].

Pada penelitian ini, model optimisasi perencanaan produksi akan diselesaikan menggunakan Firefly Algorithm (FA). Firefly Algorithm (FA) ditemukan oleh Xin-She Yang pada tahun 2008. Cara kerja FA menyerupai perilaku kunang-kunang dalam berkomunikasi, mencari mangsa dan menemukan pasangan menggunakan cahaya yang dipancarkan. Salah satu perilaku kunang-kunang yang digunakan adalah kunang-kunang yang kurang cerah akan mendekati kunang-kunang yang lebih cerah sehingga dalam hal ini posisi kunang-kunang direpresentasikan solusi dan tingkat kecerahan direpresentasikan sebagai nilai fitness [11].

Hasil simulasi menunjukkan bahwa metode FA dapat menemukan pendekatan solusi optimum pada perencanaan produksi yaitu biaya produksi, biaya pekerja, dan biaya pengadaan yang memenuhi kendala jumlah produksi, jumlah pekerja, dan jumlah pengadaan.

\section{Metode}

Metode yang digunaka dalam penelitian ini menggunakan Firefly Algorithm (FA) pada masalah optimisasi perencanaan produksi. Optimisasi perencanaan produksi merupakan salah satu optimisasi berkendala sehingga pada FA diperlukan modifikasi pada posisi kunangkunang baik pada tahap inisialisasi maupun tahap optimisasi supaya posisi kunang-kunang memenuhi semua kendala yang ada.

\subsection{Model Optimisasi Perencanaan Produksi}

Secara umum, model optimisasi perencanaan produksi adalah sebagai berikut [9] :

$$
\begin{gathered}
\min \sum_{t=1}^{T} C_{t}^{P} P_{t}+C_{t}^{W} W_{t}+C_{t}^{H} H_{t}+C_{t}^{L} L_{t}+C_{t}^{I} I_{t} \\
\text { dengan kendala : } \\
\quad P_{t} \leq n_{t} W_{t}, \quad t=1,2, \ldots, T \\
W_{t}=W_{t-1}+H_{t}-L_{t}, \quad t=1,2, \ldots, T \\
I_{t}=I_{t-1}+P_{t}-D_{t}, \quad t=1,2, \ldots, T \\
P_{t}, W_{t}, H_{t}, L_{t}, I_{t} \geq 0
\end{gathered}
$$

Model optimisasi perencanaan produksi dapat dijelaskan sebagai berikut :

$D_{t} \quad$ : jumlah unit yang diminta dalam periode $t$

$n_{t} \quad$ : jumlah unit yang diproduksi oleh setiap pekerja dalam periode $t$

$C_{t}^{P}$ : biaya produksi per unit dalam periode $t$

$C_{t}^{W}$ : biaya pekerja dalam periode $t$

$C_{t}^{H}$ : biaya pekerja yang masuk dalam periode $t$

$C_{t}^{L} \quad$ : biaya pekerja yang keluar (lay off) dalam periode $t$

$C_{t}^{I} \quad$ : biaya pengadaan dalam periode $t$

$P_{t} \quad$ : jumlah unit yang diproduksi dalam periode $t$

$W_{t} \quad$ : jumlah pekerja dalam periode $t$

$H_{t} \quad$ : jumlah pekerja yang masuk dalam periode $t$

$L_{t} \quad$ : jumlah pekerja yang keluar (lay off) dalam periode $t$

$I_{t} \quad$ : jumlah pengadaan dalam periode $t$

\subsection{Firefly Algorithm}

Firefly Algorithm (FA) ditemukan oleh XinShe Yang pada tahun 2008. Cara kerja FA menyerupai perilaku kunang-kunang dalam berkomunikasi, mencari mangsa dan menemukan pasangan menggunakan cahaya yang dipancarkan. Dalam FA, daya tarik (attractiveness) kunang-kunang ditentukan oleh tingkat kecerahan yang berhubungan dengan fungsi objective.

Tingkat kecerahan dari kunang-kunang di lokasi $x$ dapat ditentukan sebagai $f(x)$, dimana $f(x)$ adalah fungsi objective. Tetapi, jika daya tarik $\beta$ adalah relative maka ditentukan oleh kunang-kunang yang lain dan terdapat jarak $r_{i j}$ antara kunang-kunang $i$ dan kunang-kunang $j$

Perilaku kunang-kunang dapat dijelaskan sebagai berikut [10] [11] :

1. Kunang-kunang bersifat unisex. Kunangkunang memiliki ketertarikan pada kunang-kunang yang lain tanpa memandang jenis kelamin. 
2. Daya tarik bersifat proporsional pada tingkat kecerahan kunang-kunang. Kunang-kunang yang kurang cerah akan mendekati kunang-kunang yang lebih cerah.

3. Tingkat kecerahan kunang-kunang dipengaruhi oleh nilai fungsi objective.

Perilaku kunang-kunang tersebut dapat dirancang sebagai FA yaitu [2] :

1. Inisialisasi populasi kunang-kunang $x^{i}, i=1,2, \ldots$ max pop dan hitung nilai fitness $f\left(x^{i}\right), i=1,2, \ldots$ max pop

2. Tentukan kunang-kunang terbaik dalam populasi beserta posisinya

$i^{\min } \leftarrow \arg \min \left(f\left(x^{i}\right), i=1,2, \ldots, \max\right.$ pop $)$

$x^{i^{\min }} \leftarrow \arg \min \left(f\left(x^{i}\right), i=1,2, \ldots, \max\right.$ pop $)$

3. Lakukan iterasi berikut :

for $i=1$ : $\max$ pop

for $j=1: \max$ pop

if $\left(f\left(x^{j}\right)<f\left(x^{i}\right)\right)$

a. Hitung jarak (distance) antara kunangkunang $i$ dan kunang-kunang $j$

$r_{i j}=\left\|x^{i}-x^{j}\right\|=\sqrt{\sum_{t=1}^{T}\left(x_{t}^{i}-x_{t}^{j}\right)^{2}}$

b. Hitung fungsi daya tarik (attractiveness) kunang-kunang

$$
\beta \leftarrow \beta_{0} e^{-\gamma r_{i j}}
$$

c. Tentukan $u_{i}=\alpha\left(\right.$ rand $\left.-\frac{1}{2}\right)$, dengan rand $\sim U(0,1)$

d. Update perpindahan kunang-kunang $i$

$$
x^{i} \leftarrow(1-\beta) x^{i}+\beta x^{j}+u_{i}
$$

end

end

end

a. Tentukan $u_{i^{\text {min }}}=\alpha\left(\right.$ rand $\left.-\frac{1}{2}\right)$, dengan rand $\sim U(0,1)$

b. Update perpindahan kunang-kunang terbaik

$$
x^{i^{\min }} \leftarrow x^{i^{\min }}+u_{i^{\min }}
$$

4. Ulangi langkah 3 sampai aturan pemberhentian tercapai.

\subsection{FA pada Optimisasi Perencanaan Produksi}

Representasi posisi kunang-kunang yang digunakan pada optimisasi perencanaan produksi dapat dikonstruksi seperti persamaan (12)

$$
X^{i}=(P, W, H, L, I)=\left[\begin{array}{ccccc}
P_{1} & P_{2} & P_{3} & \ldots & P_{T} \\
W_{1} & W_{2} & W_{3} & \ldots & W_{T} \\
H_{1} & H_{2} & H_{3} & \ldots & H_{T} \\
L_{1} & L_{2} & L_{3} & \ldots & L_{T} \\
I_{1} & I_{2} & I_{3} & \ldots & I_{T}
\end{array}\right]
$$

Dimana $P_{t}$ adalah jumlah unit yang diproduksi dalam periode $t, W_{t}$ adalah jumlah pekerja dalam periode $t, H_{t}$ adalah jumlah pekerja yang masuk dalam periode $t, L_{t}$ adalah jumlah pekerja yang keluar (lay off) dalam periode $t, I_{t}$ adalah jumlah pengadaan dalam periode $t$.

Dalam FA, terdapat tahap inisialisasi yang harus memenuhi kendala (2)-(5). Oleh karena itu, tahap inisilisasi dapat dikonstruksi sebagai berikut :

initialization (max $H, \max L, \max p o p)$

for $i=1$ : $\max$ pop

1. Bangkitkan $H_{t}^{i} \sim U(0, \max H)$ and

$$
L_{t}^{i} \sim U(0, \max L), t=1,2, \ldots, T
$$

2. Tetapkan $W_{0}^{i}$

for $t=1: T$

$$
W_{t}^{i}=W_{t-1}^{i}+H_{t}^{i}-L_{t}^{i}
$$

end

3. for $t=1: T$

$$
P_{t}^{i} \leq n_{t} W_{t}^{i}
$$

end

4. Tetapkan $I_{0}^{i}$

for $t=1: T$

$$
I_{t}^{i}=I_{t-1}^{i}+P_{t}^{i}-D_{t}
$$

end

end 
Langkah-langkah FA pada optimisasi perencanaan produksi supaya memenuhi kendala (2)-(5) adalah sebagai berikut :

1. Inisialisasi populasi kunang-kunang dengan initialization ( $\max H, \max L, \max$ pop) dan hitung nilai fitness $f\left(x^{i}\right), i=1,2, \ldots$ max pop

2. Tentukan kunang-kunang terbaik dalam populasi beserta posisinya

$$
\begin{aligned}
& i^{\min } \leftarrow \underset{i}{\arg \min }\left(f\left(x^{i}\right), i=1,2, \ldots, \max \text { pop }\right) \\
& x^{i^{\text {in }}} \leftarrow \underset{x^{i}}{\arg \min }\left(f\left(x^{i}\right), i=1,2, \ldots, \max \text { pop }\right)
\end{aligned}
$$

3. Lakukan iterasi berikut :

for $i=1: \max$ pop

for $j=1: \max p o p$

if $\left(f\left(x^{j}\right)<f\left(x^{i}\right)\right)$

a. Hitung jarak (distance) antara kunangkunang $i$ dan kunang-kunang $j$

$$
r_{i j}=\left\|x^{i}-x^{j}\right\|=\sqrt{\sum_{t=1}^{T}\left(x_{t}^{i}-x_{t}^{j}\right)^{2}}
$$

b. Hitung fungsi daya tarik (attractiveness) kunang-kunang

$$
\beta \leftarrow \beta_{0} e^{-\gamma r_{i j}}
$$

c. Tentukan $u_{i}=\alpha\left(\right.$ rand $\left.-\frac{1}{2}\right), \quad$ dengan rand $\sim U(0,1)$

d. Update perpindahan kunang-kunang $i$

$$
\begin{aligned}
H^{i} & \leftarrow(1-\beta) H^{i}+\beta H^{j}+u_{i} \\
L^{i} & \leftarrow(1-\beta) L^{i}+\beta L^{j}+u_{i}
\end{aligned}
$$

end

end

e. Tetapkan $W_{0}^{i}$

$$
\begin{aligned}
\text { for } t & =1: T \\
W_{t}^{i} & =W_{t-1}^{i}+H_{t}^{i}-L_{t}^{i}
\end{aligned}
$$

end

$$
\begin{aligned}
& \text { f. for } t=1: T \\
& \quad P_{t}^{i} \leq n_{t} W_{t}^{i} \\
& \text { end }
\end{aligned}
$$

g. Tetapkan $I_{0}^{i}$ for $t=1: T$

$$
I_{t}^{i}=I_{t-1}^{i}+P_{t}^{i}-D_{t}
$$

end

end

a. Tentukan $u_{i^{\min }}=\alpha\left(\right.$ rand $\left.-\frac{1}{2}\right)$, dengan rand $\sim U(0,1)$

b. Update perpindahan kunang-kunang terbaik

$$
\begin{gathered}
H^{i^{\min }} \leftarrow H^{i^{\min }}+u_{i_{\text {min }}} \\
L^{i^{\min }} \leftarrow L^{i^{\min }}+u_{i^{\min }}
\end{gathered}
$$

c. Tetapkan $W_{0}^{i^{\text {inin }}}$

$$
\begin{aligned}
& \text { for } t=1: T \\
& \qquad W_{t}^{i^{\min }}=W_{t-1}^{i^{\min }}+H_{t}^{i^{\min }}-L_{t}^{i^{\min }} \\
& \text { end }
\end{aligned}
$$

d. for $t=1: T$

$$
P_{t}^{i^{i \min }} \leq n_{t} W_{t}^{i^{\min }}
$$

end

e. Tetapkan $I_{0}^{i^{\min }}$

for $t=1: T$

$$
I_{t}^{i^{\mathrm{min}}}=I_{t-1}^{i^{\mathrm{min}}}+P_{t}^{i^{\mathrm{ini}}}-D_{t}
$$

end

4. Ulangi langkah 3 sampai aturan pemberhentian tercapai.

\section{Hasil Simulasi}

Data yang digunakan dalam penelitian ini diambil dari salah satu perusahaan pupuk di Gresik, Jawa Timur selama tahun 2011-2016. Tabel 1 menunjukkan biaya per unit, Tabel 2 menunjukkan jumlah permintaan setiap periode, Tabel 3 menunjukkan unit yang diproduksi untuk setiap pekerja. Simulasi dilakukan menggunakan FA dengan parameter yang diberikan seperti Tabel 4.

Tabel 1. Biaya per Unit (dalam juta rupiah)

\begin{tabular}{lcccccc}
\hline$t$ & $\mathbf{2 0 1 1}$ & $\mathbf{2 0 1 2}$ & $\mathbf{2 0 1 3}$ & $\mathbf{2 0 1 4}$ & $\mathbf{2 0 1 5}$ & $\mathbf{2 0 1 6}$ \\
\hline$C_{t}^{P}$ & 4,00 & 4,54 & 5,17 & 5,33 & 5,71 & 5,33 \\
\hline$C_{t}^{W}$ & 7 & 7 & 7 & 7 & 7 & 7 \\
\hline$C_{t}^{H}$ & 4 & 4 & 4 & 4 & 4 & 4 \\
\hline$C_{t}^{L}$ & 2 & 2 & 2 & 2 & 2 & 2 \\
\hline$C_{t}^{I}$ & 2,46 & 3,83 & 4,34 & 4,03 & 4,63 & 4,26 \\
\hline
\end{tabular}


ISSN: 2527-3159

E-ISSN: 2527-3167

Tabel 2. Jumlah Permintaan (dalam ton)

\begin{tabular}{cc}
\hline Periode $t$ & Jumlah Permintaan \\
\hline 2011 & 4328630 \\
\hline 2012 & 5008571 \\
\hline 2013 & 5409669 \\
\hline 2014 & 5375396 \\
\hline 2015 & 5546783 \\
\hline 2016 & 5357118 \\
\hline
\end{tabular}

Tabel 3. Jumlah Unit yang Diproduksi per Pekerja (dalam ton/pekerja)

\begin{tabular}{cc}
\hline Periode $t$ & Jumlah Unit/Pekerja \\
\hline 2011 & 1060 \\
\hline 2012 & 1271 \\
\hline 2013 & 1249 \\
\hline 2014 & 1266 \\
\hline 2015 & 1285 \\
\hline 2016 & 1292 \\
\hline
\end{tabular}

Tabel 4. Parameter Firefly Algorithm

\begin{tabular}{lc}
\hline Parameter & Nilai \\
\hline Populasi maksimum & 20 \\
\hline Iterasi maksimum & 100 \\
\hline$\beta_{0}$ & 1 \\
\hline$\gamma$ & 5 \\
\hline$\alpha$ & 0,1 \\
\hline
\end{tabular}

Hasil simulasi ditunjukkan seperti Gambar 1. Pada iterasi awal, posisi kunang-kunang dipilih secara acak. Pada proses optimisasi, tingkat kecerahan kunang-kunang diupdate sehingga menghasilkan nilai fitness yang turun atau tingkat kecerahan kunang-kunang bertambah seiring bertambahnya iterasi. Dari Gambar 1, terlihat bahwa biaya minimum sebagai nilai fitness yang dikeluarkan perusahaan dalam tahun 2011-2016 adalah $2,21 \times 10^{8}$ juta rupiah.

Tabel 5 dan Tabel 6 menunjukkan solusi optimal dari optimisasi perencanaan produksi yang terdiri dari jumlah unit yang diproduksi dalam periode $t$, jumlah pekerja dalam periode $t$, jumlah pekerja yang masuk dalam periode $t$, jumlah pekerja yang keluar dalam periode $t$, dan jumlah pengadaan dalam periode $t$.

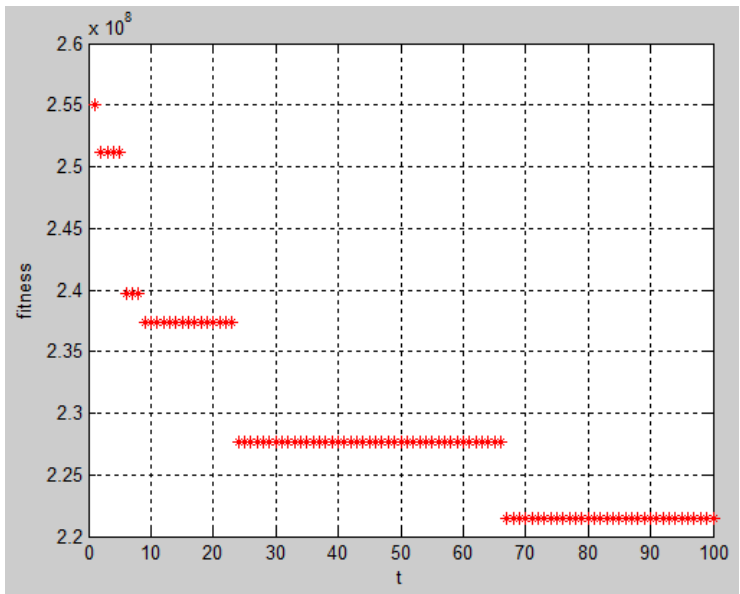

Gambar 1 Hasil Simulasi Firefly Algorithm pada Optimisasi Perencanaan Produksi

Tabel 5. Solusi Optimal pada Pekerja

\begin{tabular}{cccc}
\hline Periode $t$ & $H_{t}$ & $L_{t}$ & $W_{t}$ \\
\hline 2011 & 128 & 281 & 3194 \\
\hline 2012 & 152 & 286 & 3060 \\
\hline 2013 & 286 & 208 & 3138 \\
\hline 2014 & 217 & 256 & 3099 \\
\hline 2015 & 275 & 245 & 3129 \\
\hline 2016 & 307 & 162 & 3274 \\
\hline
\end{tabular}

Tabel 6. Solusi Optimal pada Produksi dan Pengadaan

\begin{tabular}{rcc}
\hline Periode $t$ & $P_{t}$ & $I_{t}$ \\
\hline 2011 & 2845724 & 10722261 \\
\hline 2012 & 3173632 & 8887322 \\
\hline 2013 & 3268910 & 6746563 \\
\hline 2014 & 3457387 & 4828554 \\
\hline 2015 & 3258592 & 2540363 \\
\hline 2016 & 3406271 & 589516 \\
\hline
\end{tabular}

\section{Kesimpulan}

Metode FA dapat menyelesaikan masalah optimisasi perencanaan produksi. Optimisasi perencanaan produksi merupakan salah satu optimisasi dengan kendala jumlah produksi, jumlah pekerja, dan jumlah pengadaan sehingga pada FA diperlukan modifikasi pada posisi kunang-kunang baik pada tahap inisialisasi maupun tahap optimisasi supaya posisi kunangkunang memenuhi semua kendala yang ada. Hasil simulasi menunjukkan bahwa metode FA dapat menemukan pendekatan solusi optimum pada perencanaan produksi yaitu biaya produksi, biaya pekerja, dan biaya pengadaan yang memenuhi kendala jumlah produksi, jumlah pekerja, dan jumlah pengadaan. 


\section{Referensi}

[1] Hillier, F.S., Lieberman, G.J., Introduction to Operations Research. Mc Graw Hill. (2001)

[2] Lukasik, S., Zak, S., Firefly Algorithm for Continuous Constrained Optimization Tasks.

[3] Rahmalia, D., Estimation of Exponential Smoothing Parameter on Pesticide Characteristic Forecast Using Ant Colony Optimization (ACO), Eksakta: Jurnal Ilmu-Ilmu MIPA Vol. 18 No. 1 pp. 56-63 (2018)

[4] Rahmalia, D., Particle Swarm OptimizationGenetic Algorithm (PSOGA) on Linear Transportation Problem. AIP Conference Proceeding. (2017) (020030)1-12. Surabaya.

[5] Rahmalia, D., Perbandingan Metode Analitik dan Metode Heuristik pada Optimisasi Masalah Transportasi Distribusi Semen. Prosiding Seminar Nasional Matematika dan Pembelajarannya 2016. (2016) 1164-1172. 13 Agustus, Malang.
[6] Rahmalia, D., Herlambang, T., Optimisasi Masalah Transportasi Distribusi Semen Menggunakan Algoritma Artificial Bee Colony, Multitek Indonesia Vol. 11 No. 2 (2018)

[7] Rao, S.S., Engineering Optimization: Theory and Practice. John Wiley and Sons. (2009)

[8] Taha, H.A., Operation Research: An Introduction. Pearson Prentice Hall. (2007)

[9] Techaroongruengkij, B., Prakasvudhisarn, C., Yenradee, P., A PSO Based Goal Programming Approach to Aggregate Planning of Production, Workforce, and Pricing Strategy

[10] Udaiyakumar, K.C, Chandrasekaran, M., Application of Firefly Algorithm in Job Shop Scheduling Problem for Minimization of Makespan, Procedia Engineering 97(2014)1798-1807

[11] Yang, X.S., Cui, Z., Xiao, R., Swarm Intelligence and Bio-Inspired Computation. Elsevier, Inc. (2013) 